\title{
Irrigation-assisted intraductal ultrasonography with a 3-Fr microcatheter during endoscopic retrograde cholangiography
}
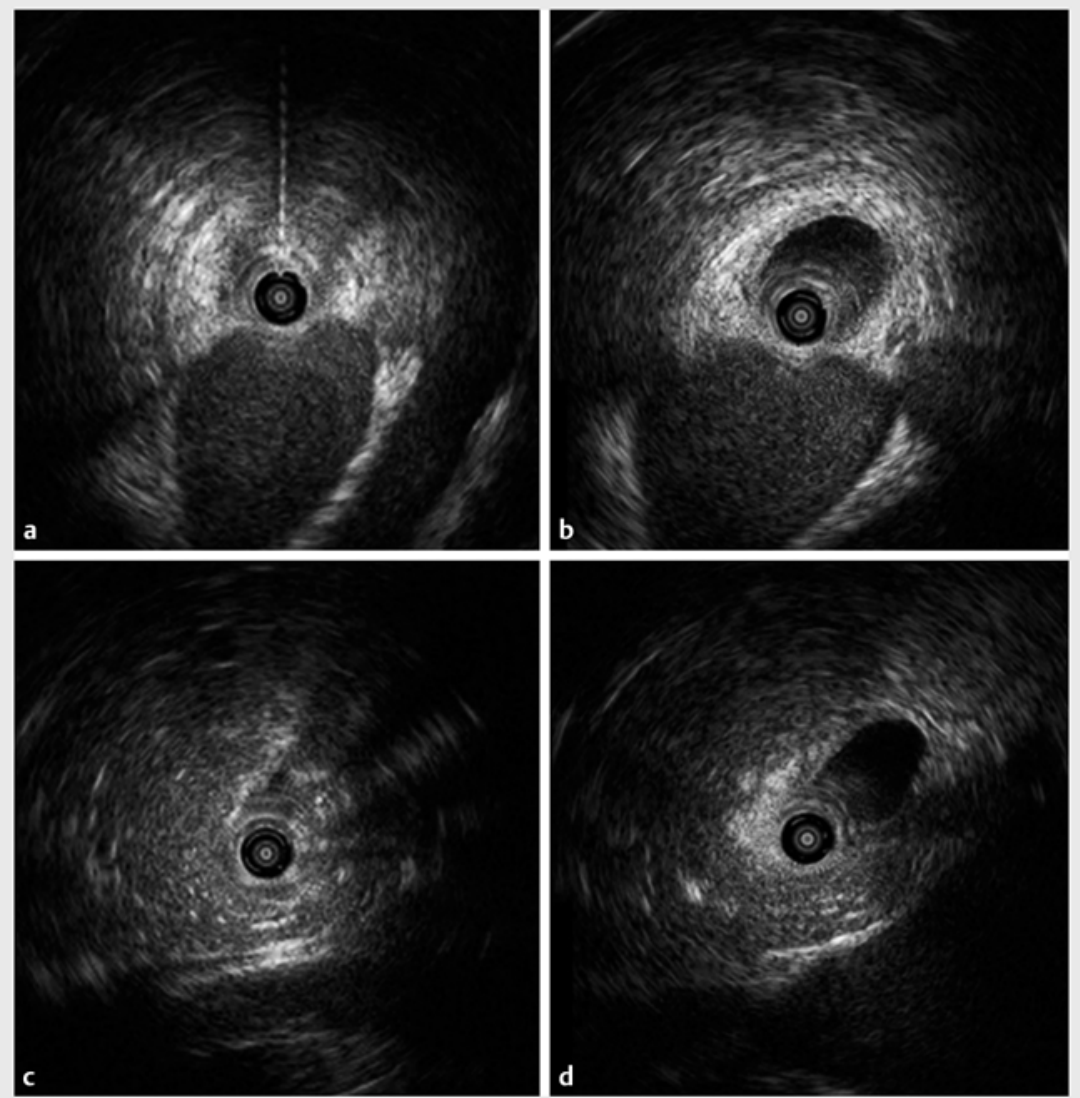

- Fig. 1 Intraductal ultrasonography (IDUS) images showing: a conventional IDUS of the extrahepatic bile duct wall; $\mathbf{b}$ irrigation-assisted IDUS in the same area as image $\mathbf{a}$; $\mathbf{c}$ conventional IDUS of the intrapancreatic bile duct wall; $\mathbf{d}$ irrigation-assisted IDUS in the same area as image $\mathbf{c}$.

Intraductal ultrasonography (IDUS) is one of the most useful intraductal modalities for investigating the structure of the biliary wall layers and for the presence of stones during endoscopic retrograde cholangiography (ERC) [1-3]. In patients with pneumobilia, however, conventional IDUS is significantly limited in its ability to provide accurate crosssectional imaging.

A 42-year-old man who had undergone endoscopic sphincterotomy for the extraction of common bile duct (CBD) stones 1 month previously experienced CBD stone recurrence. Lithotomy was performed using a side-viewing duodenoscope (TJF-260V; Olympus, Tokyo, Japan). Because of this recurrent episode, IDUS (UMG20-29R; Olympus) was performed to confirm complete stone clearance following standard CBD sweeping with a basket catheter. However, air bubbles in the CBD prevented cross-sectional imaging of the intraluminal contents and ductal layer ( $\mathbf{F i g . 1} \mathbf{a}, \mathbf{c}$ ). To overcome this limitation, we first introduced a 3-Fr microcatheter (Dimon ERCP catheter; Hanako Medical, Saitama, Japan), which is an over-the-wire microcatheter with a radiopaque tip, into the CBD. The

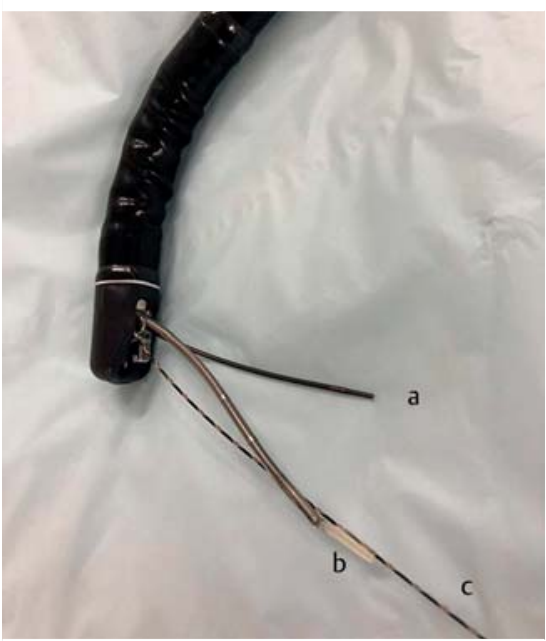

Fig. 2 Photograph of the side-viewing duodenoscope used in the "two-devicesin-one-channel" method. MC, 3-Fr microcatheter (Dimon ERCP catheter; Hanako Medical); UP, high-frequency intraductal ultrasonography probe (UMG20-29R; Olympus); GW, 0.025-inch guidewire.

IDUS probe was then advanced over the guidewire alongside the microcatheter. IDUS was performed while simultaneously flushing the CBD with quarter-diluted contrast agent via the microcatheter. This technique achieved clear imaging with coordinated manipulation of the probe and microcatheter in the same

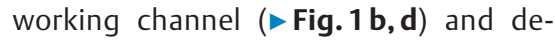
tected a tiny remnant stone in the cystic duct ( $\triangleright$ Fig. 2 ; $>$ Video 1 ).

A 3-Fr microcatheter is slim enough to enable it to be paired in the "two-devices-in-one-channel" method in endoscopic procedures. Simultaneous irrigation via the microcatheter during IDUS ameliorates acoustic coupling and produces reliable examinations that are suitable for the evaluation of the wall layers in patients with pneumobilia, as well as for the detection of stones. As the water-filling method is routinely used before endoscopic ultrasonography to evaluate invasion depth in gastrointestinal cancer, we believe irrigation assist- 


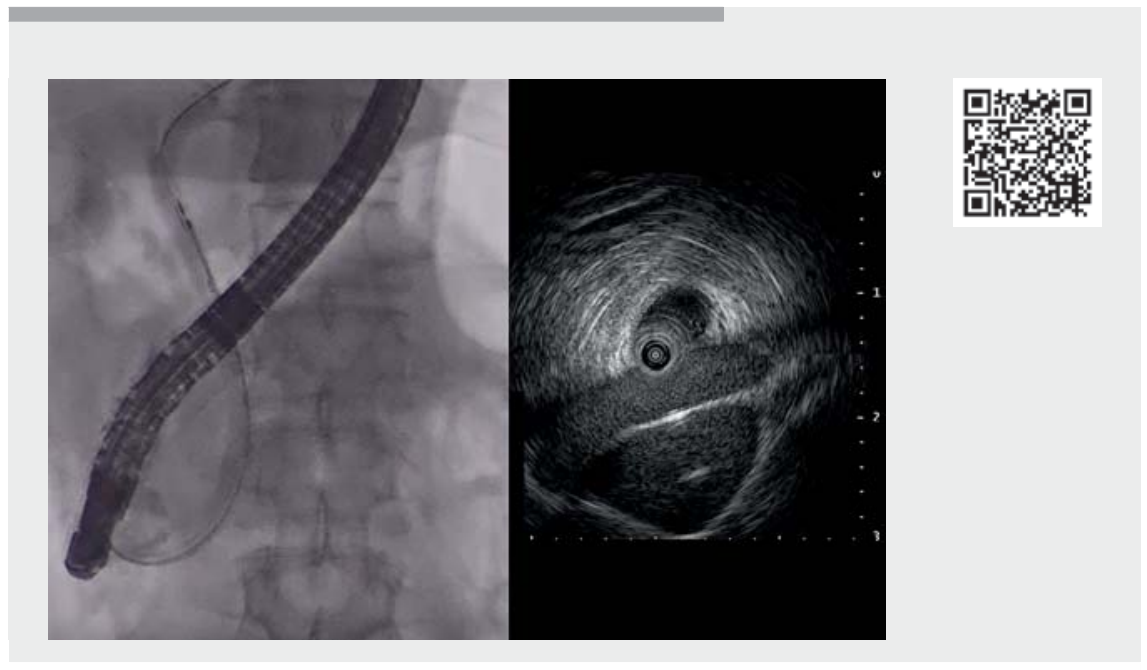

$\checkmark$ Video 1 Irrigation-assisted intraductal ultrasonography with a novel microcatheter during endoscopic retrograde cholangiography.

ance with the 3-Fr microcatheter during IDUS has promise as a routine method for pancreaticobiliary endoscopy in patients with pneumobilia.

Endoscopy_UCTN_Code_CCL_1AF_2AF_3AB

\section{Competing interests}

The authors declare that they have no conflict of interest.

The authors

Michihiro Yoshida, Itaru Naitoh, Kazuki Hayashi, Makoto Natsume, Yasuki Hori, Akihisa Kato, Hiromi Kataoka

Department of Gastroenterology and Metabolism, Nagoya City University Graduate School of Medical Sciences, Nagoya, Japan

\section{References}

[1] Moon JH, Cho YD, Cha SW et al. The detection of bile duct stones in suspected biliary pancreatitis: comparison of MRCP, ERCP, and intraductal US. Am J Gastroenterol 2005; 100: 1051-1057

[2] Kim DC, Moon JH, Choi H] et al. Usefulness of intraductal ultrasonography in icteric patients with highly suspected choledocholithiasis showing normal endoscopic retrograde cholangiopancreatography. Dig Dis Sci 2014; 59: 1902-1908
[3] Sun B, Hu B. The role of intraductal ultrasonography in pancreatobiliary diseases. Endosc Ultrasound 2016; 5: 291-299

\section{Bibliography}

Endoscopy 2022; 54: E294-E295

DOI 10.1055/a-1519-6677

ISSN 0013-726X

published online 2.7 .2021

(c) 2021. Thieme. All rights reserved.

Georg Thieme Verlag KG, Rüdigerstraße 14,

70469 Stuttgart, Germany

\section{ENDOSCOPY E-VIDEOS}

https:/|eref.thieme.de/e-videos

回通 Endoscopy E-Videos is an open access online section, 被傿 reporting on interesting cases and new techniques in gastroenterological endoscopy. All papers include a high quality video and all contributions are freely accessible online. Processing charges apply (currently EUR 375), discounts and wavers acc. to HINARI are available.

This section has its own submission website at https://mc.manuscriptcentral.com/e-videos 